\title{
Characterization of six rat strains (Rattus norvegicus) by mitochondrial DNA restriction fragment length polymorphism
}

A.W. Hilsdorf 1,2 and J.E. Krieger ${ }^{1}$

\section{Correspondence \\ J.E. Krieger \\ Laboratório de Genética e \\ Cardiologia Molecular \\ Instituto do Coração, HC, FM, USP \\ Av. Dr. Enéas $C$. Aguiar, 44 \\ 05403-000 São Paulo, SP \\ Brasil \\ E-mail: krieger@ incor.usp.br \\ Research supported by FAPESP (No. 4668-6), CNPq (No. 520696/95- \\ 6) and FINEP (No. 66.93.0023.00). \\ A.W. Hilsdorf is the recipient of \\ a Doctoral fellowship from CNPq to \\ develop graduate studies in the \\ Department of Physiology and \\ Biophysics, IB-UNICAMP.}

Received July 1, 1998

Accepted November 19, 1998

\author{
1Laboratório de Genética e Cardiologia M olecular, \\ Instituto do Coração and Departamento de Clínica M édica, \\ Faculdade de Medicina, U niversidade de São Paulo, São Paulo, SP, Brasil \\ ${ }^{2}$ Departamento de Ciências Agrárias, Universidade de Taubaté, Taubaté, SP, Brasil
}

\section{Abstract}

Restriction fragment length polymorphism (RFLP) was used to examine the extent of mtDNA polymorphism among six strains of rats (Rattus norvegicus) - Wistar, Wistar Munich, Brown Norway, Wistar Kyoto, SHR and SHR-SP. A survey of 26 restriction enzymes has revealed a low level of genetic divergence among strains. The sites of cleavage by EcoRI, NcoI and XmnI were shown to be polymorphic. The use of these three enzymes allows the 6 strains to be classified into 4 haplotypes and identifies specific markers for each one. The percentage of sequence divergence among all pairs of haplotypes ranged from 0.035 to $0.33 \%$, which is the result of a severe population constriction undergone by the strains. These haplotypes are easily demonstrable and therefore RFLP analysis can be employed for genetic monitoring of rats within animal facilities or among different laboratories.

\section{Introduction}

Rats are useful models employed to study cardiovascular physiology and to understand complex pathological states such as hypertension and diabetes mellitus (1). Rattus norvegicus is the rodent species that gave rise to all types of laboratory rat strains currently in use. In the late fifties and early sixties several strains of rats were developed for high blood pressure studies by selective intercross to fix a phenotype among individuals of outbred colonies. For instance, the spontaneously hypertensive rat (SHR) was obtained by intercrossing individuals of an outbred colony of Wistar Kyoto (WKY) rats with the highest blood pressure values (2).

\section{Key words}

- Restriction fragment length polymorphism (RFLP)

- Rattus norvegicus

- mtDNA

- Laboratory rats

- Genetic monitoring
......................
Several studies on genetic variability and phylogeny in rodents based on mitochondrial and nuclear DNA have been published (4-6). At present, anonymous markers throughout the rat genome are available for DNA "fingerprinting" (7,8). Restriction fragment length polymorphism (RFLP) analysis of the nuclear genome was used to measure the level of genetic divergence between SHR and the Wistar-Kyoto rats (9). Also, arbitrarily primed polymerase chain reaction (APPCR) was performed to develop nuclear genetic markers and to perform genetic linkage 
analysis in rat strains (10). More recently, Jacob et al. (11) used a large panel of markers to develop a genetic linkage map for rats. The power of these methods is highlighted by their use in studies to analyze complex traits such as high blood pressure and diabetes mellitus (12-14). However, these techniques are complex and are not available in most animal facilities where genetic monitoring is undertaken.

Mitochondrial DNA diversity is known to exist within the same species in different taxa such as primates (15), fishes (16), and birds (17). Intraspecific mtDNA polymorphism in Rattus norvegicus strains was observed using the endonuclease EcoRI. The fragment pattern produced by $E c o$ RI permitted the classification of different rat strains into two categories, type A and type B $(18,19)$. Brown and Simpson (20) and Hayashi et al. (21) found an extensive intra- and interspecific mtDNA polymorphism using not only EcoRI but also HhaI, HindII, Hinf III, Hinf I and HaeIII restriction endonucleases.

Maternal mode of inheritance and lack of recombination of mtDNA are features that can be used to obtain information about the female genealogy and to organize the individuals into matriarchal lineages. Due to the ease of genotyping, mtDNA polymorphism may be a useful genetic marker to monitor inbred lines in a variety of laboratories $(22,23)$.

In the present study, a broad mtDNA survey of 6 strains of Rattus norvegicus was carried out by RFLP. In addition, we established the pattern of genetic divergence among these commonly used rat strains within haplotypes that can be easily employed for genetic monitoring of animal facilities utilizing three restriction endonucleases.

\section{Material and Methods}

\section{Experimental animals}

Six strains of Rattus norvegicus com- monly used in the laboratory were investigated: Wistar, Wistar Munich, Brown Norway, Wistar Kyoto, SHR, and SHR-SP (spontaneously hypertensive rat - stroke prone). Male and female rats of $200 \mathrm{~g}$ were obtained from the animal facility at the Federal University of São Paulo. Ten animals from each strain were sampled from different matings. All procedures followed the "Guide for the care and use of laboratory animals" (DHEW Publication No. (NIH) 85-23, Revised 1985, Office of Science and Health Reports, DRR/ NIH, Bethesda, MD 20892) and the guidelines of the animal welfare act.

\section{Mitochondrial DNA isolation}

Mitochondrial DNA was extracted from 3-4 $\mathrm{g}$ of liver and heart from each rat after an overnight fast in order to decrease the glycogen content in the liver. The tissues were homogenized in TEK buffer (50 mM Tris, 10 mM EDTA, $0.2 \mathrm{M} \mathrm{KCl}, 0.25 \mathrm{M}$ sucrose, $\mathrm{pH}$ $7.5)$ and the mtDNA was isolated according to the method of Chapman and Powers (24).

\section{Restriction endonuclease digestion}

The isolated mtDNA was digested with 26 restriction endonucleases: ApaI (GGGCC/ C), AvalI (G/GWCC), BamHI (G/GATCC), $B g l$ II (A/GATCT), BssHII (G/CGCGC), ClaI (AT/CGAT), DraI (TTT/AAA), EcoRI (G/ AATTC), EcoRV (GAT/ATC), HincII (GTY/ RAC), HindIII (A/AGCTT), HhaI (GCG/C), HpaI (GTT/AAC), KpnI (GGTAC/C), MluI (A/CGCGT), NcoI (C/CATGG), NdeI (CA/ TATG), NheI (G/CTAGC), PstI (CTGCA/ G), PvuII (CAG/CTG), SacI (GAGCT/C), SalI (G/TCGAC), SmaI (CCC/GGG), XbaI (T/CTAGA), XhoI (C/TCGAG), and XmnI (GAANN/NNTTC). mtDNA was digested and incubated at $37^{\circ} \mathrm{C}$ for $3-4 \mathrm{~h}$ for complete digestion as specified by the manufacturer (Gibco, BRL, Gaithersburg, MD). The reaction products were separated by electrophoresis in $0.8 \%$ horizontal agarose gel and 
visualized under UV light following ethidium bromide staining. The images were printed or stored for future analysis (Eagle Eye System II, Stratagene).

\section{DNA size estimation}

The mobility pattern of the mtDNA fragments was compared to that of the standard marker lambda HindIII and of the 100-bp DNA ladder (Gibco, BRL). Differences in fragment mobility were measured directly from the gel image and the DNA size was estimated using the DNAGEL software (25).

\section{Data analysis}

Percent sequence divergence among mtDNA haplotypes was calculated according to the following formula: $d=\left[-\log _{\mathrm{e}} \mathrm{S}\right] / \mathrm{r}$. For a class of endonucleases, $r$ is the number of nucleotides for a recognition sequence. $S$ $=2 \mathrm{~m}_{\mathrm{xy}} /\left(\mathrm{m}_{\mathrm{x}}+\mathrm{m}_{\mathrm{y}}\right)$ where $\mathrm{m}_{\mathrm{x}}$ is the number of restriction sites for $x$ th haplotypes, $m_{y}$ the number of restriction sites observed for the $y$ th haplotype, and $\mathrm{m}_{\mathrm{xy}}$ the common number of restrictions between the xth and yth haplotype $(26,27)$. A parsimony network was constructed connecting the different haplotypes. Gains and losses at the network site are depicted as a single mutational step by a slash in the phenogram.

\section{Results}

In order to develop a simple method to monitor and test the use of mitochondrial DNA as a genetic marker for laboratory rats, we performed a systematic survey using 26 restriction enzymes. Thirteen of them have not been tested for this objective in published studies. Three of the 26 endonucleases, ClaI, NheI and SacI, were able to hydrolyze the mtDNA from the 6 Rattus norvegicus strains in only one site. Twenty endonucleases cut the DNA twice or more, but did not reveal polymorphism. Three enzymes,
XmnI, NcoI, and EcoRI, were successful in demonstrating differences in cleavage patterns which were considered to be polymorphic.

EcoRI proved to be the most informative enzyme with three different cleavage patterns found in the 6 strains studied, as previously shown. The Wistar strain mtDNA presented 6 fragments, which correspond to type A $(\alpha)$, and Wistar Munich showed 4 fragments, described as type B (ß) $(18,19)$. Wistar Kyoto, SHR, SHR-SP, and Brown Norway rats showed a different pattern that is cited as type III by Brown and Simpson (20) (Figure 1).

Two new polymorphic sites were detected during the present survey. First, $\mathrm{Nco}$ I digestion revealed two restriction patterns. Wistar Kyoto, SHR, and SHR-SP mtDNA was cleaved into two similar size fragments, whereas Wistar Munich, Wistar, and Brown Norway mtDNA samples showed a single site restriction fragment (Figure 2). The second restriction enzyme, $X m n \mathrm{I}$, also produced two restriction patterns. Wistar Kyoto, SHR, SHR-SP, Wistar, and Brown Norway mtDNA samples showed three fragments while Wistar Munich mtDNA produced only two (Figure $3)$.

The differences in cleavage patterns shown by HhaI (2 types) and HindII ( 2 types)

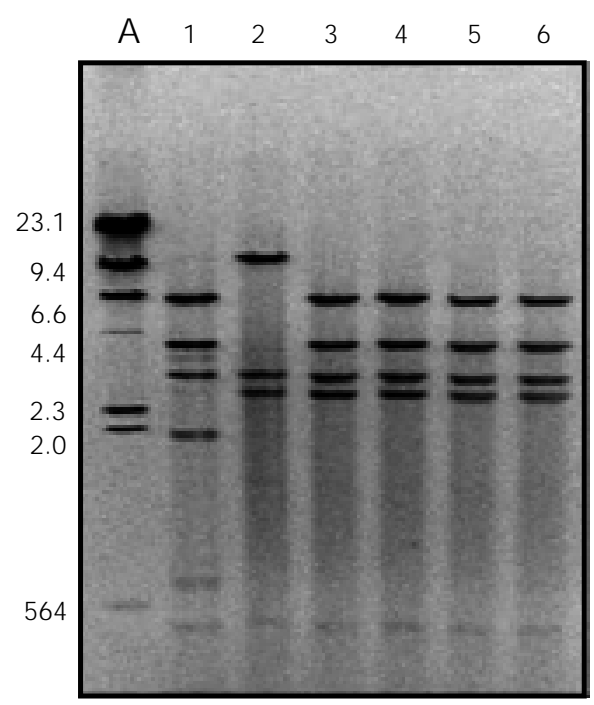

Figure 1 - EcoRI mtDNA cleavage pattern types of Rattus norvegicus strains. Lane A, $\lambda$ HindlII fragment; lane 1 , cleavage pattern I, Wistar; lane 2, cleavage pattern II, Wistar Munich; lanes 3-6, cleavage pattern III, Wistar Kyoto, SHR, SHR-SP, and Brown Norway, respectively. 
Figure 2 - Ncol mtDNA cleavage pattern types of $R$. norvegicus strains. Lane $A, \lambda$ HindlII fragment; lanes 1-3, cleavage pattern I, Wistar Kyoto, SHR, SHRSP, respectively; lanes 4-6, cleavage pattern II, Wistar, Wistar Munich, and Brown Norway, respectively.
Figure 3 - Xmnl mtDNA cleavage pattern types of $R$. norvegicus strains. Lane $A, \lambda$ HindllI fragment; lanes 1-5, cleavage pattern I, Wistar Kyoto, SHR, SHRSP, Wistar, and Brown Norway, respectively; lane 6 , cleavage pattern II, Wistar Munich.
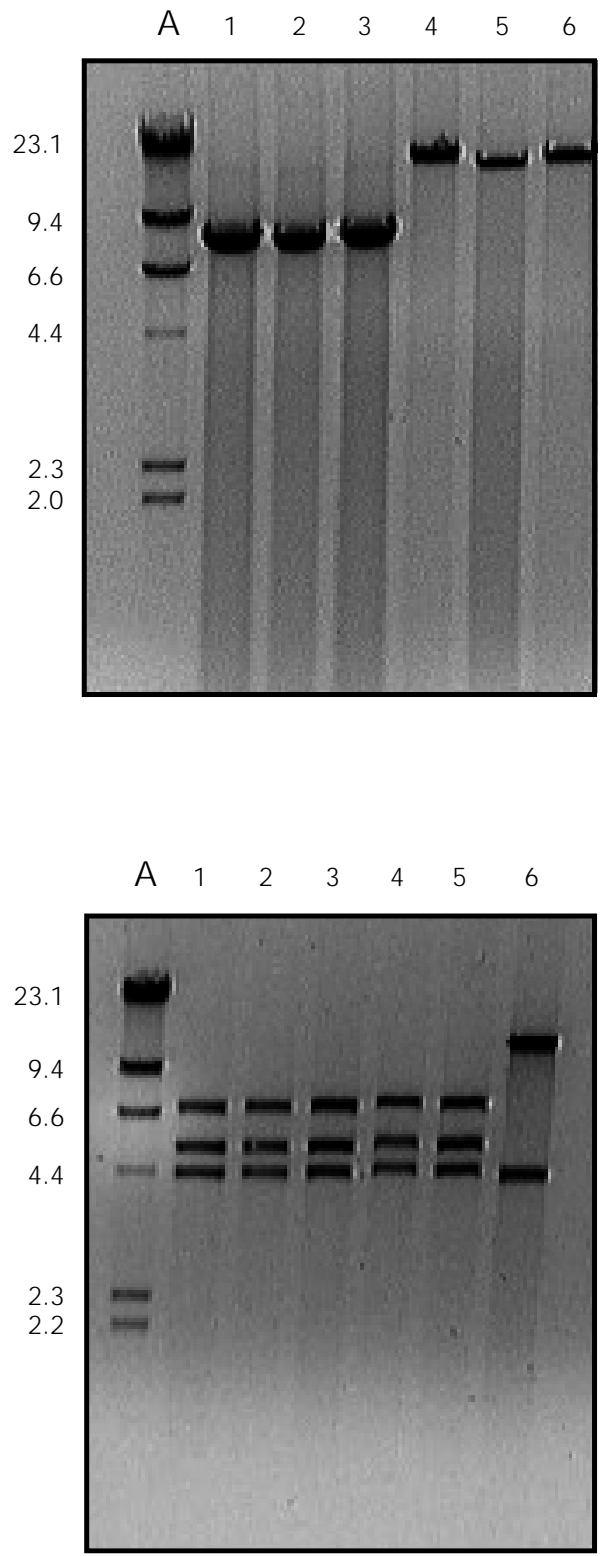

Table 1 - Mitochondrial DNA clonal lineages of 6 strains of Rattus norvegicus based on restriction sites produced by EcoRI, Ncol, and Xmnl.

The Roman numerals indicate the cleavage pattem types for each enzyme.

\begin{tabular}{ccccc}
\hline Clone & EcoRI & Ncol & Xmnl & Strains \\
\hline A & I & II & I & Wistar \\
B & II & II & Wistar Munich \\
C & III & I & I & Wistar Kyoto, SHR, SHR-SP \\
D & III & II & I & Brown Norway
\end{tabular}

among several strains of $R$. norvegicus (28) were not observed in the 6 strains presently studied. The informative enzymes HinflI and HaeIII utilized by Brown and Simpson (20) were not used in our study since the large numbers of small size fragments produced are difficult to visualize in ethidium bromide-stained gels.

The analyses of the 6 strains with the three polymorphic enzymes (EcoRI, XmnI and $N c o$ I) produced four haplotypes (Table 1). Wistar was designated as haplotype " $A$ "; Wistar Munich as "B”, Wistar Kyoto, SHR, and SHR-SP as "C", and Brown Norway as "D".

The estimated length of the mtDNA from the 6 Rattus norvegicus strains averaged $16,500 \pm 500 \mathrm{bp}$, which is in close agreement with data previously published by Gadaleta et al. (29) and Clark-Walker (30). Table 2 shows the estimated mtDNA fragment sizes produced by each polymorphic enzyme.

A parsimony network was assembled connecting the various clonal lineages according to the pattern produced by the endonuclease digestions (Figure 4). In the phenogram one can estimate the relative genetic distance by counting the number of site differences among the haplotypes. Therefore, intraspecific nucleotide diversity between all pairs of haplotypes can be calculated according to their rate of nucleotide substitutions. Percent sequence divergence (or index of nucleotide diversity) ranged from 0.035 to $0.33 \%$ (Table 3 ).

The homogeneity of the strains studied was tested by analyzing the pattern of mtDNA fragments produced by EcoRI, NcoI and XmnI in 30 Wistar Munich rats from different matings. No differences in restriction patterns were found, indicating that the animal colony tested is uniform.

\section{Discussion}

Laboratory rats undergo a severe process of selection and inbreeding in order to pro- 
duce isogenic lineages and the genetic standardization required for experimental studies (31). Rats have been one of the most frequently used animals to study cardiovascular physiology. Nonetheless, genetic variability has been identified in several strains of rats from different commercial sources as well as from the same breeding facilities, a fact that may influence interpretation of the results (32).

Genetic variation in mtDNA is expected to be small or even null since the process of achieving inbred lines begins with a few animals which possess the genetic characteristics to be selected and fixed.

The various $R$. norvegicus types can be regarded as different lineages due to the intensive inbreeding methods and also to the absence of gene flow among strains to produce rats for different experimental purposes. Consequently, the different strains may be grouped into clonal lineages and their genetic variability assessed.

As expected, our findings showed no differences among Wistar Kyoto, SHR and SHR-SP strains upon analysis with the 26 enzymes tested, which is consistent with the results found by Johnson et al. (9). This lack of divergence was expected since SHR and SHR-SP were developed from Wistar Kyoto rats by selection from a common maternal lineage. The three polymorphic enzymes identified in this work can easily be used to classify Wistar Kyoto, SHR and SHR-SP into the same haplotype (C).

Mitochondrial DNA from the Brown Norway strain exhibited the same pattern as found in SHR, SHR-SP and Wistar Kyoto upon digestion with EcoRI and XmnI. In contrast, $\mathrm{NcoI}$ produced a different cleavage pattern. Thus, Brown Norway rats were assigned to a different haplotype (D). Wistar and Wistar Munich rats were classified as clones A and B, which confirms the previously described types A and B (18). These 2 strains were classified differently upon digestion with the endonucleases EcoRI and XmnI.

Table 2 - Fragment sizes (kb) produced by EcoRI, Ncol and Xmnl restriction enzymes in mtDNA from Rattus norvegicus.

The Roman numerals indicate the cleavage pattern types associated with each polymorphic enzyme.

\begin{tabular}{|c|c|c|c|c|c|c|}
\hline \multicolumn{3}{|c|}{ EcoRI } & \multicolumn{2}{|c|}{ Ncol } & \multicolumn{2}{|c|}{$\mathrm{Xmnl}$} \\
\hline I & II & III & 1 & II & I & II \\
\hline 6.49 & 10.4 & 6.49 & 16.43 & 8.83 & 7.11 & 12.27 \\
\hline 4.11 & 3.05 & 4.11 & & 7.60 & 5.06 & 4.04 \\
\hline 3.05 & 2.54 & 3.05 & & & 4.04 & \\
\hline 1.87 & 0.46 & 2.54 & & & & \\
\hline 0.64 & & 0.46 & & & & \\
\hline 0.46 & & & & & & \\
\hline 16.6 & 16.4 & 16.6 & 16.4 & 16.4 & 16.2 & 16.3 \\
\hline
\end{tabular}

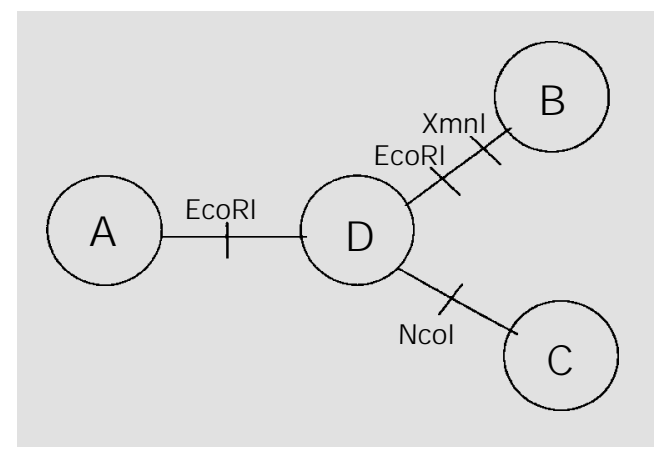

Table 3 - Matrix of percent sequence divergence among the four haplotypes obtained by mtDNA digestion with EcoRI, Ncol, and Xmnl from 6 strains of Rattus norvegicus.

\begin{tabular}{ccccl}
\hline & A & B & C & \multicolumn{1}{c}{ D } \\
\hline A & - & 0.33 & 0.14 & 0.1 \\
B & 0.33 & - & 0.25 & 0.22 \\
C & 0.14 & 0.25 & - & 0.035 \\
D & 0.1 & 0.22 & 0.035 & -
\end{tabular}

The three informative enzymes, EcoRI and those identified in the present study, $X m n I$ and $N c o I$, can be used to separate the 6 rat strains into specific haplotypes with no need for sophisticated laboratory equipment.

Various statistical approaches have been used to estimate mtDNA sequence divergence (33-35) and a range of results has been obtained. In the present study the nucleotide diversity for $R$. norvegicus ranged from 0.035
Figure 4 - Parsimony network showing restriction site gains or losses (slash in the diagram) in Rattus norvegicus mitochondrial DNA haplotypes. The DNA polymorphism is indicated on the phenogram by its restriction endonuclease. 
to $0.33 \%$, which is lower than the values found by Brown and Simpson (20), 0.4 to $1.8 \%$, and Hayashi et al. (21), $1 \%$. The lower values of genetic divergence among the four clonal lineages obtained in our study can be explained by the larger number of enzymes surveyed. It is important to note that the final result was dependent on the analysis of all the informative and non-informative enzymes. Additionally, the low divergence may be due to the severe population constriction undergone by the strains which were generated from a small number of females. The highest sequence divergence value of $0.33 \%$ was found between haplotypes A (Wistar) and B (Wistar Munich). This distance is illustrated in the parsimony network showing two restriction site losses for EcoRI and one for XmnI. Our results suggest that the Wistar rat is the ancestral strain from which all the other strains studied originated.

It is interesting to note the low level of divergence between haplotype D (Brown Norway) and the others. This is consistent with a common and recent female origin of the Brown Norway strain compared to the others even though the different coat coloration of the Brown Norway strain indicates the contrary. A wild male rat probably introduced the dark coloration phenotype during crossbreeding.

The absence of differences in mitochondrial DNA pattern among offspring from
Wistar Munich rats originating from distinct mating pairs indicated a common founder stock in the breeding facility studied. The origin of $R$. norvegicus plays an essential role in the genetic background of the various rat strains used in experimental studies. Therefore, the maintenance of genetic uniformity of laboratory rats depends on a careful monitoring of the strains.

The results obtained here suggest that the analysis of mtDNA with EcoRI, NcoI, and $X m n I$ may be a useful tool to monitor laboratory rats, preventing strain contamination and maintaining population uniformity in animal facilities. The use of specific mtDNA probes and of non-invasive techniques (36) further improved the use of mtDNA for the maintenance of the genetic quality of laboratory rats. It is important to note that sorting rat strain according to mtDNA clonal lineages does not preclude a certain level of nuclear DNA polymorphism, which may be secondary to an outbred male colony, or to incomplete generation of inbreeding.

\section{Acknowledgments}

The authors gratefully thank Juliana S. Valle, Maria E. Infante Vargas and Maria de Lourdes Junqueira for technical assistance and Dr. Ana Maria Lima de Azeredo Espin for helpful discussion and suggestions.

\section{References}

1. Rapp J (1987). Use and misuse of control strains for genetically hypertensive rats. Hypertension, 10: 7-10.

2. Okamoto K \& Aoki K (1963). Development of a strain of spontaneously hypertensive rats. J apanese Circulation J ournal, 27: 282-293.

3. Louis WJ \& Howes LG (1990). Genealogy of the spontaneously hypertensive rats: Implications for studies of inherited hypertension. J ournal of Cardiovascular Pharmacology, 16 (Suppl 7): 51-55.

4. Nevo E, Honeycutt RL, Yonekawa H, Nelson K \& Hanzawa N (1993). Mitochon- drial DNA polymorphism in subterranean mole-rats of the Spalax ehrenbergi superspecies in Israel, and its peripheral isolates. Molecular Biology and Evolution, 10: 590-604.

5. Holmes EC (1991). Different rates of substitutions may produce different phylogenies of eutherian mammals. J ournal of Molecular Evolution, 33: 208-215.

6. Hadler $\mathrm{HI}$, Dimitrijevic B \& Mahalingam R (1983). Mitochondrial DNA and nuclear DNA from normal rat liver have a common sequence. Proceedings of the $\mathrm{Na}$ tional Academy of Sciences, USA, 80:
6495-6499.

7. NabikaT, Nara Y, Ikeda K, EndoJ \& Yamori $Y$ (1991). Genetic heterogeneity of the spontaneously hypertensive rat. Hypertension, 18: 12-16.

8. Kurtz TW, Montano M, Chan L \& Kabra P (1989). Molecular evidence of genetic heterogeneity in Wistar-Kyoto rats: Implications for research with the spontaneously hypertensive rat. Hypertension, 13: 188192.

9. J ohnson ML, Perry SW, Ely DL \& Tumer ME (1993). Inconsistent divergence of mitochondrial DNA in the spontaneously 
hypertensive rat. Hypertension, 21: 10661070.

10. Kuramoto $T$, Mashimo $T \&$ Serikawa $T$ (1995). Fourteen anonymous DNA markers of laboratory rats identified with arbitrarily primed polymerase chain reaction (AP-PCR). Experimental Animals, 44: 119125.

11. J acob HJ, Brown DN, Bunker RK, Daly MJ , Dzau VJ , Goodman A, Koike G, Kren V, Kurtz T, Lemmark A, Levan G, Mao Y, Pettersson V, Pravenec $M$, Simon J S, Szpirer C, Szpirer J , Trolliet MR, Winer ES \& Lander ES (1995). A genetic linkage map of the laboratory rat, Rattus norvegicus. Nature Genetics, 9: 63-69.

12. Schork NJ, Krieger JE, Trolliet MR, Franchini KG, Koike G, Krieger EM, Lander ES, Dzau VJ \& Howard JJ (1995). A biometrical genome search in rats reveals the multigenic basis of blood pressure variation. Genome Research, 5: 164-172.

13. J acob HJ, Lindpainter $\mathrm{K}$, Lincoln SE, Kusumi K, Bunker RK, Mao Y, Ganten D, Dzau VJ \& Lander ES (1991). Genetic mapping of a gene causing hypertension in the stroke-prone spontaneously hypertensive rat. Cell, 67: 213-224.

14. Hilbert P, Lindpainter K, Beckmann J S, Serikawa T, Soubrier F, Dulbay $C$, Cartwright P, De Gouyon B, Julier C, Takahasi S, Vicent M, Ganten D, Georges M \& Lathrop M (1991). Chromosomal mapping of two genetic loci associated with blood-pressure regulation in hereditary hypertensive rats. Nature, 353: 521529.

15. Ferris $S D$, Wilson $A C \&$ Brown WM (1981). Evolutionary tree for apes and humans based on cleavage maps of mitochondrial DNA. Proceedings of the $\mathrm{Na}-$ tional Academy of Sciences, USA, 78: 2432-2436.

16. Bermingham E \& Avise J C (1986). Molecular zoogeography of freshwater fishes in the southeastern United States. Genetics, 113: 939-965.

17. Ball J r RM \& Avise J C (1992). Mitochondrial DNA phylogeography differentiation among avian populations and the evolu- tionary significance of subspecies. Auk, 109: 626-636.

18. Francisco J F \& Simpson MV (1977). The occurrence of two types of mitochondrial DNA in rat populations as detected by EcoRI endonuclease analysis. FEBS Letters, 79: 291-294.

19. Francisco J F, Brown GG \& Simpson MV (1979). Further studies on types A and B rat mtDNAs: Cleavage maps and evidence for cytoplasmic inheritance in mammals. Plasmid, 2: 426-436.

20. Brown GG \& Simpson MV (1980). Intraand interspecific variation of the mitochondrial genome in Rattus norvegicus and Rattus rattus: restriction enzyme analysis of variant mitochondrial DNA molecules and their evolutionary relationships. Genetics, 97: 125-143.

21. Hayashi J -I, Yonekawa $\mathrm{H}$, Gotoh $\mathrm{O}$, Tagashima $Y$, Moriwaki $K$ \& Yosida $T$ (1979). Evolutionary aspects of variant types of rat mitochondrial DNA. Biochimica et Biophysica Acta, 564: 202-211.

22. Cramer DV (1983). Genetic monitoring techniques in rats. Institute of Laboratory Animal Resources News, 26: 15-19.

23. Schedl HL, Wilson HD \& Horst RL (1988). Calcium transport and vitamin $\mathrm{D}$ in three breeds of spontaneously hypertensive rats. Hypertension, 12: 310-316.

24. Chapman RW \& Powers DA (1984). A Method for the Rapid Isolation of Mitochondrial DNA from Fishes. Technical Report \#UM-SG-TS-84-05. Maryland Sea Grant Program, College Park, Maryland.

25. Kieser T (1984). DNAGEL: a computer program for determining DNA fragment sizes using a small computer equipped with a graphics tablet. Nucleic Acids Research, 12: 679-688.

26. Nei $M \&$ Tajima $F$ (1983). Maximum likelihood estimation of the number of nucleotide substitutions from restriction site data. Genetics, 105: 207-217.

27. Nei M, Stephens J C \& Saitou N (1985). Methods for computing the standard errors of branching point in an evolutionary tree and their application to molecular data for human and apes. Molecular Biol- ogy and Evolution, 2: 66-85.

28. Suzuki M \& Hayashi J -I (1987). Genetic monitoring of laboratory rat strains by restriction fragment length polymorphism of mitochondrial DNA. Experimental Animals, 36: 169-175.

29. Gadaleta G, Pepe G, De Candia G, Quagliariello C, Sbisa E \& Sccone C (1989). The complete nucleotide sequence of the Rattus norvegicus mitochondrial genome: Cryptic monitoring revealed by comparative analysis between vertebrates. J ournal of Molecular Evolution, 28: 496-516.

30. Clark-Walker GD (1985). Basis of diversity in mitochondrial DNA. In: Cavalier-Smith $\mathrm{T}$ (Editor), The Evolution of Genome Size. Wiley, New York, 277-297.

31. Lindpainter K, Kreutz R \& Ganten D (1992). Genetic variation in hypertensive and "control" strains: what are we controlling for anyway? Hypertension, 19: 428-430.

32. Kurtz TW \& Morris RC (1987). Biological variability in Wistar-Kyoto rats: Implications for research with the spontaneously hypertensive rat. Hypertension, 10: 127131.

33. Upholt W (1977). Estimation of DNA sequence divergence from comparison of restriction endonuclease digests. Nucleic Acids Research, 4: 1257-1265.

34. Gotoh O, Hayashi J -I, Yonekaya $\mathrm{H}$ \& Tagashira $Y$ (1979). An improved method estimating sequence divergence between related DNA from changes in restriction endonuclease cleavage sites. J ournal of Molecular Evolution, 14: 301310.

35. Nei M \& Li W (1979). Mathematical model for studying genetic variation in terms of restriction endonucleases. Proceedings of the National Academy of Sciences, USA, 76: 5269-5273.

36. Billington N \& Hebert PDN (1990). Technique for determining mitochondrial DNA markers in blood samples from walleyes. American Fisheries Society Symposium, 7: 492-498. 